\title{
Perioperative Management of Diabetes: A Review
}

\author{
Md. Nazmul Kayes', N M N Kabir Prodhan², Refat Hossain Malik³
}

\begin{abstract}
Diabetes increases the requirements of surgery as well as perioperative morbidity and mortality. Careful preoperative evaluation and treatment of cardiac and renal diseases, intensive intraoperative and postoperative management are essential to optimize the best outcome. Stress hyperglycemia in response to surgery, osmotic diuresis and hypoinsulinemia can lead to life threatening complications like ketoacidosis or hyperglycemic hyperosmolar syndrome. Wound healing is impaired by hyperglycemia and chance of postoperative wound infection is more in diabetics. Therefore aseptic precautions must be taken. Adequate insulin, glucose, fluid and electrolytes should be provided for good metabolic control. Though some current study reveals that oral hypoglycemic agents can be used for the effective management of perioperative diabetes; the adverse effects of newly introduced agents need more clinical observations. Subcutaneous administration of insulin as in Sliding Scale may be a less preferable method, because of unreliable absorption and unpredictable blood glucose. Intravenous administration of rapid onset soluble (short acting) insulin as in Alberti (GIK) regimen, is safe and effective method controlling perioperative hyperglycemia. Patient with type 1 diabetes needs frequent monitoring of glucose, electrolytes and acid-base balance as chance of high hyperglycemia and ketoacidosis is more. In case of emergency surgery assessment for diabetic ketoacidosis (DKA) and meticulous management is essential. Postoperative pain and hyperglycemia should be treated carefully to avoid complications.
\end{abstract}

Keywords: Perioperative management; diabetes; complication; anesthesia.

Delta Med Col J. Jul 2014;2(2): 71 - 76

\section{Introduction}

The global incidence of diabetes mellitus is rising and the number of affected people is projected to exceed 300 million by the year 2025.1 The prevalence of $2.8 \%$ in 2000 is estimated to be $4.4 \%$ in $2030 .^{2}$ Diabetes mellitus leads to many systemic diseases that require surgical treatment. It is observed that diabetic patients undergo surgical procedures at a higher rate than nondiabetic patients. 3,4 Hyperglycemia has negative consequences on the entire organ system of the body. ${ }^{5-9}$ The risk of perioperative complication associated with diabetes mellitus is increased. The mortality rate in diabetic patients undergoing surgery is also increased.10,11 Long term control of blood glucose reduces the rate and severity of complications. But even short term glycemic control in hospitalized patients can

1. Assistant Professor, Department of Anesthesia, ICU \& Pain Management, Delta Medical College \& Hospital, Dhaka, Bangladesh.

2. Assistant Professor, Department of Anesthesia, ICU \& Pain Management, Delta Medical College \& Hospital, Dhaka, Bangladesh.

3. Associate Professor, Department of Anesthesia, ICU \& Pain Management, Delta Medical College \& Hospital, Dhaka, Bangladesh.

Correspondence: Dr. Md. Nazmul Kayes. e-mail: nkayes.kiron@gmail.com 
significantly lower morbidity and mortality. Aim of this review is to aware physicians to control perioperative diabetes meticulously to reduce complications.

\section{Glucose Physiology 12}

Liver and pancreas play the major role in glucose metabolism. Glucose metabolism occurs to a laser extent in peripheral tissues. Liver uptakes glucose and stores as glycogen and performs gluconeogenesis as well as glycogenolysis. The catabolic hormones namely epinephrine, glucocoticoids and growth hormone raise blood glucose concentration and in response to the raised blood glucose level the pancreatic beta cell secretes insulin, which lowers blood glucose concentration. 12 Peripheral tissues use glucose for energy needs, thus lowering blood glucose levels.

\section{Effect of hyperglycemia13-21}

Hyperglycemic patients are susceptible to develop infection as host defenses against infection is inhibited. Hyperglycemia also impairs wound healing through its harmful effects on collagen formation and decreases wound tensile strength. Healing at anastomotic site is severely impaired if blood glucose is not controlled. As the incidence of coronary artery disease is increased in diabetics, the risk of ischaemic heart disease, cerebrovascular infarction and renal ischaemia is increased. In patients with type 2 diabetes chance of hyperglycemic hyperosmolar non-ketotic states (HONKS) is more than that of diabetic ketoacidosis and hyperosmolar non ketotic coma (HONC) that may carry higher mortality. Hyperglycemia can also induce insulin resistance through glucose toxicity.

\section{Perioperative management}

\section{A. Preoperative evaluation 22}

The status of the patient's diabetes and surgical risk factors are to be evaluated first. The method of anesthesia to be used, the characteristics of the procedure to be performed, and laboratory values are also important. In case of elective surgery, potential problems should be identified, treated, and stabilized before surgery. Assessment of metabolic control and any diabetes associated complications, including cardiovascular disease, autonomic neuropathy and nephropathy is the main target of preoperative evaluation. Silent myocardial ischemia occurs relatively often in patients with diabetes. So all diabetic patients should be evaluated at least by ECG but echocardiography and stress test are often justified if there is suspicion for cardiovascular disease. Patients with diabetic autonomic neuropathy may develop perioperative hypotension, so resting tachycardia, peripheral neuropathy and orthostatic hypotension should be sought. Serum creatinine and creatinine clearance rate (CCR) should be measured to exclude the possibility of diabetic nephropathy. Diabetic patients with abnormal creatinine clearance or proteinuria have a greater risk of developing acute renal failure.

\section{B. Anesthetic consideration $23-29$}

- Diabetic patients should be the first case in the morning to minimize the starvation period.

- Most stable analgesia and anesthesia should be provided to limit surgical stress induced hyperglycemia.

- Judicious analgesics should be used.

- Both regional and general anaesthesia may be given in diabetics.

- Regional anesthesia blunts the stress response to surgery.

- Spinal or epidural anesthesia modulates catecholamine secretion preventing hyperglycemia and ketoacidosis. This effect could continue in the postoperative period.

- Aseptic precautions and sterile techniques must be maintained both for anesthesia and surgery.

- In diabetic autonomic neuropathy, profound hypotension may occur. So regarding hemodynamic stability ideal anesthetics should be used.

- Ability of lipid metabolism is decreased in diabetic patient, so drugs in lipid imulsion (e.g. Propofol) should be used cautiously. Single dose of Propofol is almost safe, but prolonged infusions for sedation in intensive care may increase the risk of hyperlipidemia.

- May have difficult airway (stiff joint syndrome). So difficult intubation protocol should be exercised and a skilled anesthetist should handle the case. 
- Severe hypoglycemia can delay recovery from general anesthesia as consciousness is impaired.

- Beta blocker drugs increase the blood glucose level in those who don't have diabetes but may worsen sugar control in those with diabetes and also blunt warning symptoms when hypoglycemia occurs.

- Patients suspected for gastroparesis should receive a prokinetic drug before administration of general anesthesia to decrease the incidence of gastric acid aspiration.

- Maintaining temperature is important as hypothermia can lead to peripheral insulin resistance.

- Ketoacidosis can develop during the periods of major stress in patients with type 1 diabetes. So these patients should be monitored by arterial blood gas analysis during and after major surgery and managed accordingly.

\section{Control of blood glucose}

As diabetic patients are more susceptible to develop numerous perioperative complications, close monitoring is imperative to control blood glucose and prevent hypoglycemia and very high hyperglycemia. Though some current studies suggested that oral hypoglycemic agents can be used for the effective management of perioperative diabetes; it is to be considered that the adverse effects of newly introduced agents need more clinical observations. Subcutaneous administration of insulin as in Sliding Scale may be a less preferable method, because of unreliable absorption and unpredictable blood glucose concentration. Intravenous administration of rapid onset soluble (short acting) insulin as in Glucose-insulinpotassium (GIK) systems (Alberti regimen), is safe and effective method controlling perioperative hyperglycemia. ${ }^{30,31}$

We should provide adequate insulin to the patient to counteract the catabolic process that develops in response to surgery. Glucose needs to be provided to meet the increased metabolic needs caused by surgical stress as well as the basal metabolic requirements. Major surgery and emergency surgery especially trauma or surgery related to infective process requires more concentration. Treatment regimen depends upon type of diabetes, usual treatment and extent of surgery.

Patients with type 2 diabetes on diet alone can be managed without insulin. 32 Close observation including hourly glucose measurement is essential in operation theatre. If the blood glucose rises $>8.0$ $\mathrm{mmol} / \mathrm{L}$, Alberti (GIK) regimen should be considered.

If type 2 diabetic patient on oral hypoglycemic agent (OHA) comes for major surgery, it is better to stop OHA 48 hours before surgery and convert to short acting insulin.23 Alberti (GIK) regimen is relatively safe in this situation because they provide insulin and glucose in the same solution. 33 Metformin needs not to be stopped, as risk of lactic acidosis is extremely low. 34 Morning dose of metformin should be omitted.

In case of minor surgery OHA should be omitted on the day of surgery and close observation is needed. If blood glucose rises above $8.6 \mathrm{mmol} / \mathrm{L}$ Alberti regimen should be adopted. In such cases continuous i.v. infusion of insulin is superior to intermittent subcutaneous bolus or intravenous boluses. 35

Patients with type 1 diabetes should stop taking long acting insulin at least 24 hours before surgery. Intermediate acting insulin may be continued until the evening before surgery. 36 Every patient of type 1 diabetes undergoing surgery should be managed with insulin. The glucose-insulin infusion is the satisfactory method of avoiding harmful metabolic consequences of starvation and surgical stress. GIK infusion is a simple reliable way for controlling the blood glucose and it should be started in preoperative period. Blood glucose level should be measured frequently and accurately throughout the perioperative period. Glucose level should be kept between 6.6 to $9.9 \mathrm{mmol} / \mathrm{L} .37$

\section{The Alberti GIK regimen for perioperative glycemic control: 38}

A solution of $500 \mathrm{ml}$ of $10 \%$ glucose containing 15 $\mathrm{U}$ of rapid onset soluble insulin with $10 \mathrm{mmol} \mathrm{KCl}$ is started at a rate of $100 \mathrm{ml} / \mathrm{hr}$ (i.e. $3 \mathrm{U} / \mathrm{hr}$ ). Blood glucose is checked 2 hourly and insulin is adjusted according to results (Table I). 
Table I: Perioperative glycemic control

\begin{tabular}{ll}
\hline Blood glucose $(\mathrm{mmol} / \mathrm{L})$ & \multicolumn{1}{c}{ Action } \\
\hline$<6.5$ & Infuse solution containing $10 \mathrm{U}$ insulin $(2 \mathrm{U} / \mathrm{hr})$ \\
$>6.4$ to $<11.1$ & Infuse solution containing $15 \mathrm{U}$ insulin $(3 \mathrm{U} / \mathrm{hr})$ \\
$>11$ & Infuse solution containing $20 \mathrm{U}$ insulin $(4 \mathrm{U} / \mathrm{hr})$ \\
\hline
\end{tabular}

Continue to adjust in 5-U steps as necessary.

\section{Glucose, insulin, fluid and electrolyte management}

Glucose, insulin, potassium and fluids are the factors that need to be considered meticulously.

Sufficient glucose is to be given to prevent hypoglycemia. It is recommend that 5-10 gm of dextrose is given per hour (70 kg patient) in the form of $5 \%$ or $10 \%$ dextrose in aqua. 39,40 An easy way is to give $0.1 \mathrm{gm} / \mathrm{kg} / \mathrm{hr}$ in adult patient and 0.3 $\mathrm{gm} / \mathrm{kg} / \mathrm{hr}$ in pediatric patients to prevent hypoglycemia. Normal saline $(0.9 \%$ sodium chloride) may be needed to prevent hyponatremia for long term infusions.

The beta cells in the pancreas secret insulin in response to glucose concentrations. Even the most sophisticated artificial insulin delivery systems cannot replicate this response. During surgery alterations in blood flow makes the absorption of insulin more unpredictable. Soluble rapid onset insulin is used in perioperative infusions due to its short half life ( $5 \mathrm{~min})$ and duration of action $(<20$ $\mathrm{min}$ ). Usually 1 unit of regular insulin is required to reduce blood glucose level 25 to $30 \mathrm{mg} / \mathrm{dl}$ except in some cases like liver disease, obesity, severe infection and steroid therapy where insulin requirements are increased. Insulin can be given either with glucose solution or by a separate syringe pump. ${ }^{41}$

Serum potassium levels should be measured at least before and after surgery. Several factors can influence serum potassium levels during surgery. Insulin stimulates the uptake of potassium into cells while dehydration and hyperglycemia can move potassium out of the cells and into the blood. Acidosis can result in hyperkalemia due to exchange of intracellular potassium for extracellular hydrogen ions. In diabetics with normal renal function and normal serum potassium levels, 10 to $15 \mathrm{mEq}$ of potassium should be added per $500 \mathrm{ml}$ of $10 \%$ glucose containing fluid.38,42 This should be adjusted according to plasma concentrations of potassium.

Any other fluids needed intraoperatively should be non-glucose containing like $0.9 \%$ sodium chloride solution. It is better to avoid Ringer's lactate solution, as lactate is gluconeogenic precursor and is rapidly metabolized resulting in higher blood glucose concentration. But the role of lactate to the acid-base disturbance is generally small. 43

\section{E. Emergency surgery}

Usually most of the diabetic patient who need emergency surgery will not be in good metabolic control at that time and may present with diabetic ketoacidosis (in type 1 diabetic patients) or hyperglycemic hyperosmolar syndrome (in type 2 diabetic patients). ${ }^{37}$ Except some life threatening surgical conditions (torrential and uncontrolled haemorrhage or acutely compromised airway) patients always require full stabilization before anesthesia and surgery. 37 To optimize metabolic status surgery should be delayed for 4-6 hours, if possible. 41

\section{F. Post operative management}

No specific protocol is recommended for glycemic control in postoperative care unit or intensive care unit (ICU). 44 Patient treated with GIK infusion intraoperatively, should be treated similarly in the postoperative period. Blood glucose level should be measured hourly and insulin dose should be adjusted according to a "glucose-feedback" formula. 45 The patient must start taking food as soon as possible. If the blood sugar is near normal or normal, preoperative drug regimen should be started. Analgesia should be maintained meticulously to reduce stress. 46

\section{Summary}

Though opinions differ regarding management, it is proved over recent years that proper preoperative evaluation, treatment of complications and good glycemic as well as metabolic control improve the outcome and reduce perioperative morbidity and mortality in diabetic patients. 


\section{References}

1. International Diabetes Federation [Internet]. Diabetes Atlas 2003. [cited 2014 Apr 26]. Available from: http://www.idf.org/diabetesatlas.

2. Wild S, Roglic G, Green A, Sicree R, King H. Global Prevalence of Diabetes Estimates for the Year 2000 and Projections for 2030. Diabetes Care. 2004;27(5):1047-53.

3. Galloway JA, Shuman CR. Diabetes and Surgery. Am J Med. 1963;34:177-91.

4. Goldmann DR. Surgery in Patients with Endocrine Dysfunction. Med Clin North Am. 1987;71:499-509.

5. Godoy DA, Napoli MD, Biestro A, Lenhardt R. Perioperative Glucose Control in Neurosurgical Patients. Anesthesiology Research and Practice [Internet]. 2012 [cited 2014 Apr 26];2012. Available from: http://www. hindawi. com/journals/ arp/2012/ 690362.

6. Turina M, Fry DE, Polk HC Jr. Acute Hyperglycemia and the Innate Immune System: Clinical, Cellular, and Molecular Aspects. Critical Care Medicine. 2005;33(7):1624-33.

7. Prakash A, Matta BF. Hyperglycaemia and Neurological Injury. Current Opinion in Anaesthesiology. 2008;21(5):565-69.

8. Tomlinson DR, Gardiner NJ. Glucose Neurotoxicity. Nature Reviews Neuroscience. 2008;9(1):36-45.

9. Oddo M, Schmidt JM, Mayer SA, Chiol'ero RL. Glucose Control after Severe Brain Injury. Current Opinion in Clinical Nutrition and Metabolic Care. 2008;11(2):134-39.

10. Hickman MS, Schwesinger WH, Page CP. Acute Cholecystitis in the Diabetic. A Case-Control Study of Outcome. Arch Surg. 1988;123:409-11.

11. Risum O, Abdelnoor M, Svennevig JL, Levorstad K, Gullestad L, Bjørnerheim R, et al. Diabetes Mellitus and Morbidity and Mortality Risks after Coronary Artery Bypass Surgery. Scand J Thorac Cardiovasc Surg. 1996;30(2):71-75.

12. Johnston DG, Pertnet A, McCulloch A, Blesa-Malpica G, Alberti KG. Some Hormonal Influences on Glucose and Ketone Body Metabolism in Normal Human Subjects. Ciba Found Symp. 1982;87:168-91.

13. Golden SH, Peart-Vigilance C, Kao WH, Brancati FL. Perioperative Glycemic Control and the Risk of Infectious Complications in a Cohort of Adults with Diabetes. Diabetes Care. 1999;22:1408-14.
14. Zerr KJ, Furnary AP, Grunkemeir GL, Bookin S, Kanhere V, Starr A. Glucose Control Lowers the Risk of Wound Infections in Diabetics after Open Heart Operations. Ann Thorac Surg. 1997;63:356-61.

15. Furnary AP, Zerr KJ, Grunkemeir GL, Starr A. Continuous Intravenous Insulin Infusion Reduces the Incidence of Deep Sternal Wound Infection in Diabetic Patients after Cardiac Surgical Procedures. Ann Thorac Surg. 1999;67:352-62.

16. Gottrup F, Andreassen TT. Healing of Incisional Wounds in Stomach and Duodenum: The Influence of Experimental Diabetes. J Surg Res. 1981;31:61-68.

17. McMurry JF Jr. Wound Healing with Diabetes Mellitus. Better Glucose Control for Better Wound Healing in Diabetes. Surg Clin North Am. 1984;64:769-78.

18. Verhofstad HJ, Hendriks T. Complete Prevention of Impaired Anastomotic Healing in Diabetic Rats Requires Preoperative Blood Glucose Control. Br J Surg. 1996;83:1717-21.

19. Rodriguez BL, Lau N, Burchfiel CM, Abbott RD, Sharp DS, Yano K, et al. Glucose Intolerance and 23-Year Risk of Coronary Heart Disease and Total Mortality: The Honolulu Heart Program. Diabetes Care. 1999;22(8):1262-65.

20. Lorber D. Nonketotic Hypertonicity in Diabetes Mellitus. Med Clin North Am. 1995;79:39-52.

21. Rossetti L, Giaccari A, DeFronzo RA. Glucose Toxicity. Diabetes Care. 1990;13(6):610-30.

22. Tetsuro $\mathrm{T}$, Hiroshi $\mathrm{K}$, Yoshihiko $\mathrm{T}$, Miyako $\mathrm{K}$, Hiroshi N, Ritsuko YH, et al. Asymptomatic Coronary Heart Disease in Patients with Type 2 Diabetes with Vascular Complications: A Cross-Sectional Study. BMJ Open [Internet]. 2011[cited 2014 Apr 26];1(2). Available from: http://bmjopen.bmj.com/content/1/2/e000139.full.

23. McAnulty GR, Robertshaw HJ, Hall GM. Anaesthetic Management of Patients with Diabetes Mellitus. Br J Anaesthesia. 2000;85:80-90.

24. Escalante DA, Kim DK, Garber AJ. Atherosclerotic Cardiovascular Disease. In: DeFronzo RA, editor. Current Therapy of Diabetes Mellitus. St. Louis: Mosby; 1998.p.176-82. 
25. Wicklmayr M, Rett K, Dietz G, Mehnart H. Comparison of Metabolic Clearance Rates of MCT/LCT and LCT Emulsions in Diabetics. J Parenteral Enteral Nutr. 1988;12:68-71.

26. McAnulty GR, Robertshaw HJ, Hall GM. Anaesthetic Management of Patients with Diabetes Mellitus. Br J Anaesth. 2000;85:80-90.

27. Salzarulo HH, Taylor LA. Diabetic "Stiff Joint Syndrome" as a Cause of Difficult Intubation. Anesthesiology. 1986;64:366-68.

28. Sinclair RCF, Faleiro RJ. Delayed Recovery of Consciousness after Anaesthesia. Contin Educ Anaesth Crit Care Pain. 2006;6(3):114-18.

29. Cueni-Villoz N, Devigili A, Delodder F, Cianferoni S, Feihl F, Rossetti AO, et al. Increased Blood Glucose Variability during Therapeutic Hypothermia and Outcome after Cardiac Arrest. Crit Care Med. 2011;39(10):2225-31.

30. Furnary AP, Wu Y, Bookin SO. Effect of Hyperglycemia and Continuous Intravenous Insulin Infusions on Outcomes of Cardiac Surgical Procedures: The Portland Diabetic Project. Endocrine Practice. 2004;10(Suppl 2):S21-33.

31. Krinsley JS. Association between Hyperglycemia and Increased Hospital Mortality in a Heterogeneous Population of Critically Ill Patients. Mayo Clin Proc. 2003;78:1471-78.

32. Thompson J, Husband DJ, Thai AC, Alberti KG. Metabolic Changes in the Non-Insulin-Dependent Diabetic Undergoing Minor Surgery: Effect of Glucose-Insulin-Potassium Infusion. Br J Surg. 1986;73:301-304.

33. Thomas DJ, Platt HS, Alberti KG. Insulin-Dependent Diabetes during the Peri-Operative Period. An Assessment of Continuous Glucose-InsulinPotassium Infusion, and Traditional Treatment. Anesthesia. 1984;39:629-37.

34. Joana S, Susana C, Vitor M, Luis C, Camila T, Pedro F, et al. Metformin-Induced Lactic Acidosis: A Case Series. J Med Case Reports. 2007;1:126.

35. Christiansen CL, Schurizek BA, Malling B, Knudsen L, Alberti KG, Hermansen K. Insulin Treatment of the Insulin-Dependent Diabetic Patient Undergoing Minor Surgery. Continuous Intravenous Infusion Compared with Subcutaneous Administration. Anaesthesia. 1988;43:533-37.
36. Albarti KGMM. Diabetes and Surgery. Anaesthesiology. 1991;74:209-11.

37. Hall CJ, Batchelor AM. Anesthetic Management of Patients with Endocrine Disease. In: Healy TEJ, Knight PR, editors. A Practice of Anaesthesia. 7th ed. London:Arnold; 2003.p.811-27.

38. Gill GV, Albarti K. The Care of the Diabetic Patient during Surgery. In: Alberti K, Zimmett P, DeFronzo $\mathrm{RA}$, Keen $\mathrm{H}$, editors. International Textbook of Diabetes Mellitus. 2nd ed. Chickester: John Wiley \& Sons; 1997.p.1243-53.

39. Pezzarosa A, Taddei F, Cimicchi MG. Perioperative Management of Diabetic Subjects: Subcutaneous Vs Intravenous Insulin Administration during Glucose-Potassium Infusion. Diabetes Care. 1988;11:52-58.

40. Husband DJ, Thai AC, Alberti KGMM. Management of Diabetes during Surgery with Glucose-Insulin-Potassium Infusion. Diabetic Med. 1986;3:69-74.

41. Wall RT. Endocrine Disease. In: Hines RL, Marschaff KE, editors. Anaesthesia and Co-Existing Disease. 7th ed. India: Elsevier; 2009.p.365-406.

42. Albarti KGMM, Thomas DJB. The Management of Diabetes During Surgery. Br J Anaesth. 1979;51: 693-710.

43. Watkins PJ, Smith JS, Fitzgerald MG, Malins JM. Lactic Acidosis in Diabetes. Brit med J. 1969;1:744-47.

44. Wilson M, Weinreb J, Hoo GW. Intensive Insulin Therapy in Critical Care: A Review of 12 Protocols. Diabetes Care. 2007;30(4):1005-11.

45. Watts NB, Gebhart SSP, Clark RV, Phillips LS. Postoperative Management of Diabetes Mellitus: Steady-State Glucose Control with Bedside Algorithm for Insulin Adjustment. Diabetes Care. 1987;10(6):722-28.

46. Adams HA, Saatweber P, Schmitz CS, Hecker H. Postoperative Pain Management in Orthopaedic Patients: No Differences in Pain Score, but Improved Stress Control by Epidural Anaesthesia. Eur J Anaesthesiol. 2002;19(9):658-65. 